\title{
Design and Simulation of Single Stage Amplifier Using 2N2222A Transistor
}

\author{
Y. Abdullahi, B.B. Sahabi
}

\begin{abstract}
An amplifier is an electronic device that amplifies the weak signal or increases the strength of a weak signal. It can either be a separate piece of equipment or an electrical circuit contained within another device. Every device or circuit, be it analog or digital requires signal amplification at one level or the other during their functioning. Considering the most basic amplifiers i.e. single-stage amplifiers which are the basic building block of all the amplifiers, be it a multi-stage amplifier or a differential amplifier. This paper presents the analysis of the parameter of a single stage signal transistor amplifier using 2N2222A transistor base on maximum rating of the transistor. A Complete Common Emitter Transistor Amplifier was design ,the battery voltage $\left(V_{C C}\right)$, collector resistor $\left(R_{C}\right)$, emitter resistor $\left(R_{E}\right)$, bias resistors $R_{1}$ and $R_{2}$, additional resistor $R g$ between the emitter resistor and the transistor, values of capacitors ( input, output and emitter) were calculated. Actual performance of the complete circuit was tested using Multisim 9 Soft ware, the resistance at which the amplifier instantaneously generates Gain, the range of the Input Voltage at which the amplifier has different Output Voltage and different Gain, the saturation point of amplifier, the cut-off frequencies, the Passband or Bandwidth (BW) of the amplifier, the relationship between additional Resistor $\left(\mathbf{R}_{\mathrm{g}}\right)$, Input $\operatorname{Voltage}\left(V_{\text {in }}\right)$, frequency respond and Gain were determined and presented graphically.
\end{abstract}

Index Terms - Simulation, 2N2222A, Transistor, Single Stage, Amplifier.

\section{INTRODUCTION}

Electronics essentially deals with study of semiconductor devices and has emerged as the most important branch of engineering (Singh, 2008). Electronics devices are being used in computer based system as a set or an arrangement of element that are organized to accomplish some predefined goal by processing information (Puntambekar, 2010; Abu-Rub et al., 2014).

They are capable of performing the following functions (Christopher, 2017): Rectification, Control, Amplification, Conversion of light into electricity and vice versa, etc.

Amplifiers are used extensively in electronic circuits to make an electronic signal bigger without affecting it in any other way(Pal, 2010). An amplifier is an electronic device that increases the power of a signal. It does this by taking energy from a power supply and controlling the output to match the input signal shape but with larger amplitude(Yan, 2015).

Amplifier can be classified basically as: Current Amplifier, Voltage Amplifier, Transconductance Amplifier,

Y. Abdullahi, Department of Science Laboratory Technology. Umaru Ali Shinkafi Polytechnic Sokoto

B.B. Sahabi, His Department of Science Laboratory Technology. Umaru Ali Shinkafi Polytechnic Sokoto
Transresistance Amplifier (Kularatna, 2008). Apart from the basic types, amplifiers can also be categorized by their operation, application or characteristics (Personnel, 1970; Morris, 2001; Clayton \& Winder, 2003; Kumar, 2004;Elbert, 2008; Glisson, 2011; Pannenborg, 2012) as : Power Amplifiers, Operational Amplifiers (Op-Amps), Valve or Vacuum Tube Amplifiers, Klystron, Instrument Amplifiers, Distributed Amplifiers, Transistor Amplifiers, etc.

There are three terminals in a transistor: emitter, base and collector terminals. When a transistor is to be connected in a circuit, four terminals are required; two for the input and two for the output. This occurs by making one terminal of the transistor common to both input and output terminals there by the input is fed between this common terminal and one of the other two terminals while the output is obtained between the common terminal and the remaining terminal (Shashidhar \& House, 2013).

Accordingly; a transistor can be connected in a circuit in the following three ways: Common Base (CB), Common Emitter(CE), and Common Collector (CC) connection. Each circuit connection has specific advantages and disadvantages (Mehta, 2008).

In this work, single stage amplifier was designed with $2 \mathrm{~N} 2222 \mathrm{~A}$ transitor using Common Emitter (CE) configuration.

\section{TRANSISTOR AMPLIFIER DESIGN}

A transistor with proper circuitry can raises the strength of a weak signal and thus acts as an amplifier (Shashidhar \& House, 2013) as shown in Figure 1.

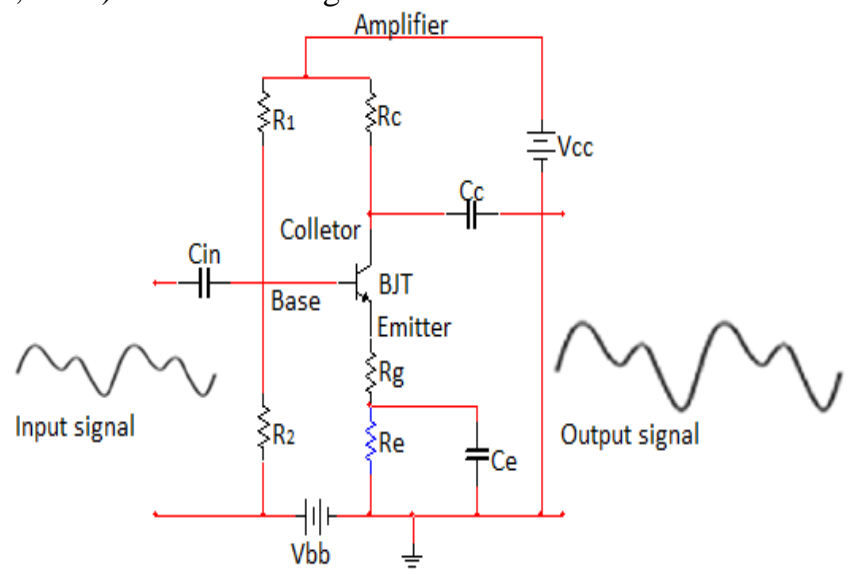

Figure 1: Common Emitter Transistor Amplifier Circuit

The weak signal is applied between emitter-base junction and output is taken across the load $\mathrm{R}_{\mathrm{C}}$ connected in the collector circuit.

In order to achieve faithful amplification, the input circuit 
should always remain forward bias. To do so, a DC voltage $\mathrm{V}_{\mathrm{BB}}$ is applied in the input circuit in addition to the signal. This DC voltage is known as bias voltage and its magnitude is such that it always keeps the input circuit forward biased regardless of the polarity of the signal. A weak signal applied in the input circuit appears in the amplified form in the collector circuit. It is in this way that a transistor acts as an amplifier. The circuit is common emitter amplifier circuit since the emitter is common to both the input circuit and the output circuit.

$\mathrm{Rc}$ is called the collector resistor and $\mathrm{Re}$ the emitter resistor. Re is actually two resistors in series one of which will be call $\mathrm{Rg}$ and is called the "gain" resistor since it controls the voltage gain or amplification, $\mathrm{Rg}$ will be important as it sets the overall gain of the amplifier (Godse \& Bakshi, 2009).

$\mathrm{R}_{1}$ and $\mathrm{R}_{2}$ are called the bias resistors and they help to set the base current $I_{b}$ by making the base emitter voltage at least $\mathrm{V}_{\mathrm{be}}=0.6 \mathrm{~V}$ for silicon transistors(Joseph, Halkiadakis, Bernal, \& Maiullo, 2016). The emitter resistor has the purpose of controlling "thermal runaway" which can burn up a transistor (Dailey, 2011).

The three basic rules for transistor amplifier design are (Godse \& Bakshi, 2009):

1. The base-emitter voltage is always biased in the forward direction about 0.6-0.7 volts for silicon transistors for the base-emitter junction to behave like a diode and a diode has a constant voltage drop .

2. The current amplification of the transistor $\beta$ to be large (typically100-300) since small changes in the base current $I_{b}$ produce large changes in the collector current $I_{c}$ and this is the basic idea behind transistor operation.

3. The collector current and the emitter current are to be almost the same size i.e. $I_{c} \approx I_{e}$.

Due to conservation of charge, it follows that:

$$
I_{e}=I_{b}+I_{c}
$$

Since the collector current $I_{c} \gg I_{b}$ it follows that $I_{c}=I_{e}$.

To design a transistor circuit, the values of the following components are to be determined:
i. Battery Voltage, $V_{c c}$;
ii. Operating Point;
iii. Collector and Emitter Resistors;
iv. Choice of the Bias Resistors $\mathrm{R}_{1}$ and $\mathrm{R}_{2}$;
v. Choice of $\mathrm{Rg}$;
vi. Choice of Capacitors
vii. Complete Circuit Diagram

\section{A. Choosing Battery Voltage ( $\left.V_{c c}\right)$}

The battery voltage, $V_{c c}$ is chosen such that it must be less than the maximum voltage the transistor can handle between the collector and emitter.

The Data Sheet of the Transistor (2N2222A) is as shown in Table 1 (Godse, 2009).
Table 1: Data sheet of 2N2222A Transistor

\begin{tabular}{|c|c|c|c|}
\hline Parameter & Condition & Max & Min \\
\hline $\begin{array}{cc}\text { Collector } & \text { base } \\
\text { voltage, } \mathrm{V}_{\mathrm{CBO}} & \end{array}$ & $\begin{array}{l}\text { Open } \\
\text { emitter }\end{array}$ & - & $75 \mathrm{~V}$ \\
\hline $\begin{array}{l}\text { Collector emitter } \\
\text { voltage, } \mathrm{V}_{\mathrm{CEO}}\end{array}$ & Open base & - & $40 \mathrm{~V}$ \\
\hline $\begin{array}{l}\text { Collector current } \\
\text { (DC) }, \mathrm{I}_{\mathrm{C}}\end{array}$ & & - & $\begin{array}{l}800 \\
\mathrm{~mA}\end{array}$ \\
\hline $\begin{array}{c}\text { Total } \\
\text { dissipation, } P_{\text {tot }}^{\text {power }}\end{array}$ & $\begin{array}{c}T_{a m b} \\
25^{\circ} \mathrm{C}\end{array}$ & - & $\begin{array}{l}500 \\
\mathrm{~mW}\end{array}$ \\
\hline $\begin{array}{l}\text { DC current gain, } \\
h_{F E}\end{array}$ & $\begin{aligned} \mathrm{I}_{\mathrm{C}} & =10 \mathrm{~mA} ; \\
\mathrm{V}_{\mathrm{CE}} & =10 \mathrm{~V}\end{aligned}$ & 75 & - \\
\hline $\begin{array}{r}\text { Transition } \\
\text { frequency, } f_{t}\end{array}$ & $\begin{aligned} \mathrm{I}_{\mathrm{C}} & =20 \mathrm{~mA} \\
\mathrm{~V}_{\mathrm{CE}} & =20 \mathrm{~V}\end{aligned}$ & $\begin{array}{l}300 \mathrm{M} \\
\mathrm{Hz}\end{array}$ & - \\
\hline $\begin{array}{l}\text { Turn off time, } \\
t_{\text {off }}\end{array}$ & $\begin{array}{l}I_{\text {Con }}= \\
150 \mathrm{~mA} ; I_{\text {Bon }} \\
=15 \mathrm{~mA} ; \\
I_{\text {Boff }}= \\
-15 \mathrm{~mA}\end{array}$ & & $\begin{array}{l}250 \\
n S\end{array}$ \\
\hline
\end{tabular}

The absolute maximum rating, $\mathrm{V}_{\mathrm{CEO}}$ of $2 \mathrm{~N} 2222 \mathrm{~A}$ Transistor is $40 \mathrm{~V}$. The battery voltage is chosen to be less than half the maximum $\mathrm{V}_{\mathrm{CEO}}$ since this allows for an addition of AC voltage due to amplification so that the transistor does not burn out (Gates, 2001).

Based on suitability and availability, $V_{C C}$ is chosen to be $12 \mathrm{~V}$.

\section{B. Choosing an Operating Point}

Operating Point is the DC values of $I_{c}, I_{b}$, and $V_{c e w h i c h}$ are the steady state values(Patrick \& Fardo, 2008). When an AC input voltage is applied to the amplifier, there are deviations from these values which are denoted by lower case letters $i_{c}, i_{b}$, and $v_{c e}$ (Silver \& Wilson, 2008). The point is to be chosen as follows:

i. Choose an $\mathrm{I}_{\mathrm{C}}$ such that the transistor actually does amplify;

ii. Given the value of $I_{C}$, and gain, the base current $I_{B}$ at the operating point is determined from:

$$
I_{b}=\frac{I_{c}}{\beta}
$$

iii. The operating point collector-emitter voltage, $V_{c e}$ is determined within the range as:

$$
\frac{V_{\text {battery }}}{3}<V_{c e}<\frac{V_{\text {battery }}}{2}
$$

A $V_{c e}$ somewhere in this range will allow for amplification of a maximum input voltage without distortion. For this design, $V_{\text {battery }}=12 \mathrm{~V} ; \beta=200$. Substituting these values gives:

$$
\begin{aligned}
& V_{c e}=V_{\text {battery }} / 3=12 / 3=4 \mathrm{~V} \\
& V_{c e}=\frac{V_{\text {battery }}}{3}=\frac{12}{3}=4 \mathrm{~V}
\end{aligned}
$$

This is the collector emitter voltage at operating point. For 
this value, the transistor might have

$$
I_{c}=4 \mathrm{~mA}
$$

Therefore, $I_{b}=\frac{\frac{4 \times 10^{-s}}{200}}{200}=0.00002=0.02 \mathrm{~mA}=20^{\mu} \mathrm{A}$

This value might be just large enough for measuring.

These value of $V_{c e}=4 \mathrm{~V}, I_{c}=4 \mathrm{~mA}$ and $I_{b}=0.02 \mathrm{~mA}$ when $\beta=200$, is known as DC operating point.

\section{Choosing the Collector and Emitter Resistors}

The purpose of the collector resistor $R_{c}$ is to set the collector current $I_{c}$ as well as the emitter- collector voltage $V_{c e}$. In other words, $R_{c}$ helps to set the transistor at the operating point of the amplifier. The purpose of the emitter resistor $R_{e}$ is to prevent thermal runaway. If the emitter resistor is not present, the collector current might increase as the transistor heats up. As a result of $I_{b}=\frac{I_{c}}{\beta}$ there is then an increased in base current which further heats up the transistor until the transistor burns up. This effect is a cause of Amplifier instability. According to rule; chosen the voltage across $R_{e}$ equal the voltage across $R_{c}$. It follows that $R_{e} \approx R_{c}$ if we follow this rule. The collector current is almost the same size as the emitter current that is $I_{c} \approx I_{e}$.), Kirchoff's loop rule says the voltage across $R_{e}$, plus the voltage across $R_{c}$, plus $V_{c e}$ equal the battery voltage $V_{\text {battery }}$ (Kramer, 2012).

$$
V_{c c}=I_{c} I_{c}+V_{c e}+I_{e} R_{e}
$$

(4)

$$
\begin{aligned}
& \text { But } I_{c}=I_{c} \text { and } R_{c}=R_{e} \\
& V_{c c}=2 I_{c} R_{c}+V_{c e} \\
& R_{c}=\frac{V_{c c}-V_{c e}}{2 I_{c}}
\end{aligned}
$$

(5)

$$
\begin{aligned}
& R_{c}=\frac{12-4}{2 \times 4 \times 10^{-8}}=\frac{8}{0.008}=1000 \Omega \\
& \therefore R_{c}=R_{e}=1000 \Omega=1 \mathrm{k} \Omega
\end{aligned}
$$

\section{The Choice of the Bias Resistors $R_{1}$ and $R_{2}$}

The bias resistors $R_{1}$ and $R_{2}$ essentially work as a voltage divider for the battery voltage $V_{\text {battery }}$ (Nair \& Deepa, 2013). The values of $R_{1}$ and $R_{2}$ are chosen so that the base-emitter junction is biased in the forward direction at least 0.6 volts since otherwise the transistor will not work. The bias resistors ae to be large compared with $R_{e}$ and $R_{e}$ so that the Voltage divider works the same way regardless of the size of $I_{c \text { and }} I_{b}$ (Chaudhary, 2014). Disregard the rest of the circuit in the process of determining $R_{1}$ and $R_{2}$ so a simplified circuit is shown in figure 2. A current $I_{2}$ goes through resistors $R_{1}$ and $R_{2}$ and a current $I_{b}$ just goes through $R_{1}$ and enters the base from the Connection with $R_{1}$ and $R_{2}$. Conservation of current allows us to conclude the current in $R_{1}$ is the sum of these currents that is $\left(I_{2}+I_{b}\right)$ (Kramer, 2012). The voltage between the transistor base and the ground is $V_{b e}=0.6$ volts plus the voltage across the emitter resistor equal to $I_{2} R_{2}$ (Kramer, 2012).

$$
I_{2} R_{2}=V_{b e}+V_{e}
$$

(6)

$$
\begin{aligned}
& \text { But } V_{c e}=V_{c e}+V_{e} \\
& V_{e}=V_{c c}-V_{c e} \\
& V_{e}=12-4=8 \mathrm{~V} \text { and } V_{b e}=0.6 \mathrm{~V} \\
& \therefore I_{2} R_{2}=0.6+8=8.6 \mathrm{~V} \text { and } R_{2}=\frac{8.6}{I_{2}} \\
& \text { Also } V_{c c}-I_{1} I_{1}-V_{b e}=0 \\
& \text { But } I_{1}=\left(I_{2}+I_{b}\right) \\
& \therefore R_{1}=\frac{V_{c c}-V_{b e}}{\left(I_{2}+I_{b}\right)}
\end{aligned}
$$

Cookbook Rule: It is a good idea to choose $I_{2} \gg I_{b}$, Our Cookbook rule is

$$
I_{2}=25^{\times} I_{b}=25^{\times} 0.00002=0.0005 \mathrm{~A} \text {. (Neglecting }
$$
$\left.I_{b} \ll I_{2}\right)$

$$
\begin{aligned}
& R_{1}=\frac{12-0.6}{0.0005}=\frac{11.6}{0.0005}=22800 \Omega=22.8 \mathrm{k} \Omega \text { and } R_{2}= \\
& \frac{8.6}{0.0005}=17200 \Omega=17.2 \mathrm{k} \Omega
\end{aligned}
$$

The values of $R_{1}=22.8 \mathrm{k} \Omega$ and $R_{2}=17.2 \mathrm{k} \Omega$ was chosen.

\section{E. The Choice of $R g$}

The input voltagele is entirely AC since the input capacitor $V_{\text {input }}$ blocks any DC voltage from getting to the transistor Also, the emitter capacitor $C_{e}$ will be chosen so that it effectively short circuits $\mathrm{AC}$ voltages around $R_{e}$. The voltage between the emitter and base is fixed at 0.6 volts DC and there is no AC voltage between the emitter and base. The entire AC input voltage appears across $R_{g}$ so that in terms of the AC emitter current $I_{a}$ we have from Ohm's law (Avison, 2014).

$$
i_{e}=\frac{V_{\text {input }}}{R_{g}}
$$

The output capacitor serves to block the DC from the output voltage so the output voltage is entirely AC. The output AC voltage $V_{\text {output }}$ is given by

$$
V_{\text {output }}=i_{c} R_{c}=i_{e} R_{c}
$$

Since to a good approximation $i_{\theta} \approx i_{c}$, the battery acts as a short or just a wire for $\mathrm{AC}$ so the top of the collector resistor is at the ground potential as far as AC is concerned.

$$
\therefore V_{\text {output }}=\frac{R_{c}}{R_{g}} V_{\text {input }}
$$

From which the AC gain $\mathrm{g}$ is

$$
g=\frac{V_{\text {output }}}{V_{\text {input }}}=\frac{R_{c}}{R_{g}}
$$


Now $R_{c}$ has already been determined, the amplifier gain $\mathrm{g}$ must be less than $\beta$ the current gain of the transistor.

$$
\therefore R_{g}=\frac{R_{c}}{g}
$$
suppose we want resistor $R_{g}$.

$$
R_{g}=\frac{1000}{25}
$$

$25=40 \Omega$. If Probably NOT found a resistor with this exact value in the lab so use one as close as possible.

\section{F. The Values of the Capacitors}

There are additionally three capacitors they do not play a role in the Basic transistor amplifier design which mainly involves setting DC voltages (Knight, Bird, \& May, 2016).

The relevant part of the amplifier as far a choosing $V_{\text {input }}$ concerned. The resistor and capacitor act as a voltage divider of the input voltage. The voltage across the resistor $V_{R}$ is

$$
V_{R}=\frac{R}{\sqrt{R^{2}+\frac{1}{\omega^{2} c^{2}}}} V_{\text {input }}
$$

Where $\omega=2 \pi f$ and $\mathrm{f}$ is the frequency of the signal generator that provides the input voltage. The resistor $R=R_{2}$ and the capacitor $c=C_{\text {input }}$. If the amplifier is for audio frequencies, then the lowest $\mathrm{f}=20 \mathrm{~Hz}$ (U. A. B. A. P. Godse, 2010). Choose c so that $V_{R}=\frac{V_{\text {input }}}{2}$ at the lowest audio frequency so that at the lowest audio frequency, half the input voltage appears across the resistor. So the equation can be write as

$$
\begin{aligned}
& v_{R}=\frac{V_{\text {input }}}{2}=\frac{2 V_{R}}{V_{\text {input }}}=\frac{V_{\text {input }}}{V_{\text {input }}}=1 \\
& \frac{V_{R}}{V_{\text {input }}}=\frac{1}{2} \\
& \frac{1}{2}=\frac{R}{\sqrt{R^{2}+\frac{1}{\omega^{2} c^{2}}}} \\
& 4 R^{2}=R^{2}+\frac{1}{\omega^{2} c^{2}} \\
& 4 R^{2} \omega^{2} c^{2}=\omega^{2} c^{2} R^{2}+1 \\
& 3 R^{2} \omega^{2} c^{2}=1 \\
& =(2 \times 3.142 \times 20)^{2}=1.5795462^{\times 10^{4}} \mathrm{rad} / \mathrm{sec} \\
& \therefore C_{\text {input }}=\frac{1}{\sqrt{3 R_{2}^{2} \omega^{2}}}=\frac{1}{3.7441672 \times 10^{06}}= \\
& 0.000000267=0.267 \times 10^{-6}=0.267 \mu \mathrm{F}
\end{aligned}
$$

. This is the value of input capacitor. The output capacitor is determined by similar reasoning since AC (but not DC) is passed along to the output which may be a speaker or another stage of amplification. Choose $C_{\text {input }}$ in the lab as close to the above value as possible.

Choosing the output capacitor, the output capacitor can be chosen using a similar argument to finding the input capacitor value. However, in this case, the role of the output capacitor is to make sure the DC voltage is not passed along to a second amplifier stage thus distorting the bias voltage of that stage. Also, the output voltage is developed across the output capacitor and the output voltage can be taken as half the total AC voltage across $C_{\text {output }}$ and $R_{c}$. The voltage across the resistor $V_{R}$ is

$$
\begin{aligned}
& V_{R}=\frac{R}{\sqrt{R^{2}+\frac{1}{\omega^{2} c^{2}}}} V_{0} \\
& V_{R}=\frac{V_{\text {output }}}{2} \\
& \frac{V_{R}}{V_{\text {output }}}=\frac{1}{2} \\
& \therefore C=\frac{1}{\sqrt{3 R^{2} \omega^{2}}}
\end{aligned}
$$

Where,

$R^{2}=R_{c}^{2}=(1000)^{2} \Omega, \omega^{2}=(2 \pi f)^{2}=$

$(2 \times 3.142 \times 20)^{2}=1.5795462 \times 10^{2}$

$\mathrm{rad} / \mathrm{sec}$, and $c=C_{\text {output }}$. Substituting this value we have $C_{\text {output }}=4.5938118 \times 10^{-6}=4.5938118 \mu F$.

This is the output capacitor.

Choosing the emitter capacitor, the emitter capacitor can be a short circuit for $\mathrm{AC}$ around the emitter resistor. The time constant of the resistor and capacitor is $T=R C$ (Gates, 2001). Where $T=\frac{1}{f}$ and $f=20 H_{Z}$ is the lowest AC frequency, $\quad R=R_{e \text { is already known }}(R=1000 \Omega)$. So the value of $C=C_{e}$ can be compute specifically as

$$
\begin{aligned}
& \text { From } T=R C \\
& C=\frac{T}{R} \quad \text { where, } \quad T=\frac{1}{f} \text { and } f=20 \mathrm{H}_{Z}, \\
& R=R_{e}=1000 \Omega, C=C_{\theta} \\
& \therefore C_{e}=\frac{T}{R_{e}} \\
& C_{\theta}=\frac{0.05}{100}=0.00005=50 \times 10^{-6}=50 \mu \mathrm{F} .
\end{aligned}
$$

This is value of emitter capacitor.

\section{G. The Complete Common Emitter Transistor Amplifier}

Base of the values of $R_{c}=R_{e}=1 K, R_{1}=22.8 K_{\Omega}$, $R_{2}=17.2 \mathrm{~K} \quad \Omega, \quad C_{\text {input }}=0.267 \mu \mathrm{F}$, $C_{\text {output }}=4.593811 \mu \mathrm{F}, C_{\text {e3 }}=50 \mu \mathrm{F}, V_{c c}=12 \mathrm{~V}$ since $12 \mathrm{~V}$ is readily available in the lab and $R_{g}=\frac{R_{c}}{g}$ which is the chosen for a particular gain. The complete common emitter transistor amplifier circuit is indicated below: 


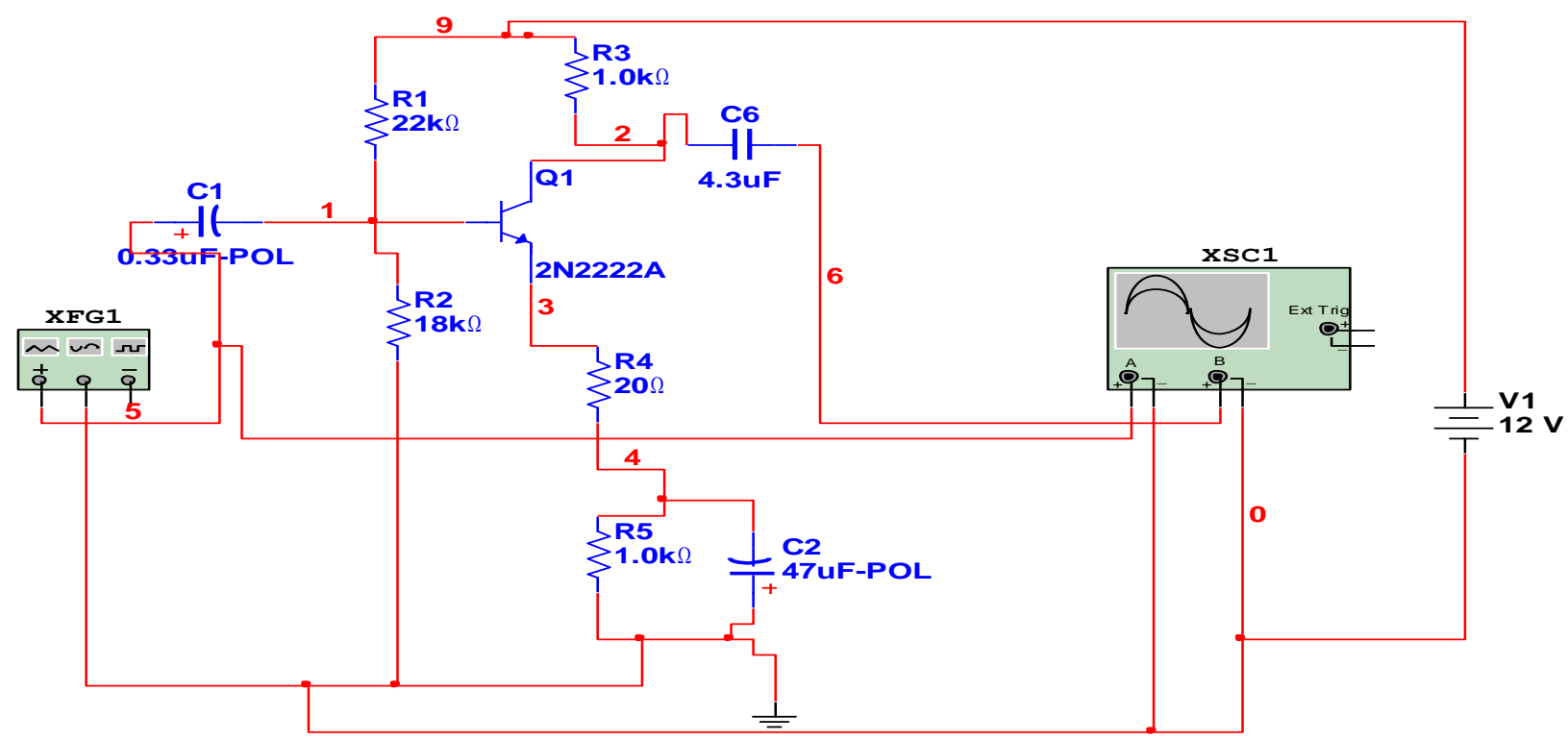

Fig .2. Complete Common Emitter Transistor Amplifier

\section{Simulated PERFORMANCE}

Circuit simulations were performed using the Multisim 9 simulator. Function generator was used to provide the amplifier input signal for test. For all tests, the function generator amplitude was set to provide a peak-to-peak sinusoidal input to the amplifier. The amplifier input and output amplitude level was identified using Oscilloscope. Based on selected values for the implementation, the corresponding simulated gains are also indicated in the table for more detailed plots of the simulated performance are given where the simulated curves using measured component values are presented.

\section{A. Results and Discussions}

Based on actual performance tested using Multisim 9 soft ware, the additional Resistor $\left(\mathrm{R}_{\mathrm{g}}\right)$, Input Voltage $\left(\mathrm{V}_{\text {in }}\right)$, and Frequency the Gain was calculated and relationship between them was determined graphically

At constant Frequency $(10 \mathrm{KHz})$ and Input Voltage $(20 \mathrm{mV})$ varying the Resistor $\left(R_{g}\right)$ the Gain was determined graphically shown in the fig below.

$$
\text { Gain } \quad \begin{aligned}
y=979.0 e^{-240} \\
R^{2}=0.956
\end{aligned}
$$

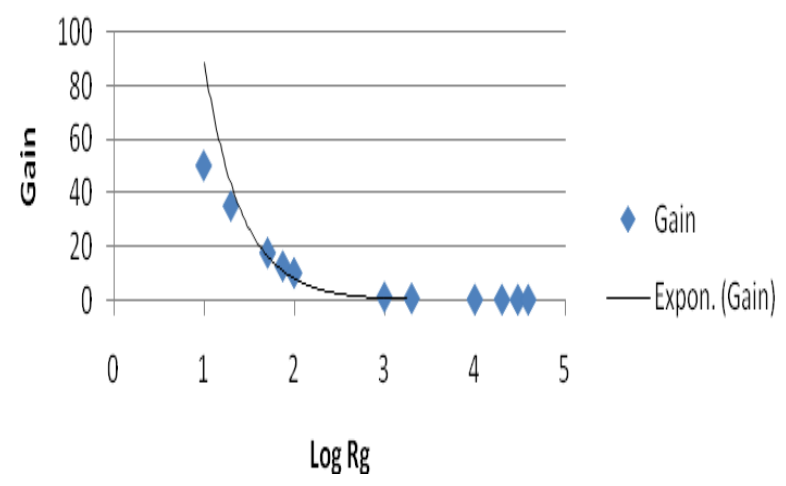

Figure3; the graph of Gain against $\log$ Resistance $\left(\mathrm{R}_{\mathrm{g}}\right)$. Figures, above shows the graph of Gain against log
Resistance $\left(\mathrm{R}_{\mathrm{g}}\right)$. It indicates that the resistance at which the amplifier instantaneously generates Gain can be observed by looking at the first data point that has resistance $10 \Omega$, Gain of 50 and resistance of $40 \mathrm{~K}$, Gain of $0.0025 \Omega$, these indicate that increases in resistance would cause decreases in Gain produced by the amplifier. It can be observed from graph that the empirical relation between Gain and Resistance is $\mathbf{y}=$ 979.01e $\mathrm{e}^{-2.406 x}$ this is the exponential relation which is the best among the different relation. The coefficient of determination $\mathbf{R}^{2}=\mathbf{0 . 9 5 6 9}$ which indicate that the correlation is very high The equation can be used to estimate the Gain at any particular Resistance.

At constant Frequency $(10 \mathrm{KHz})$ and Resistor $\mathrm{R}_{\mathrm{g}}(30 \Omega)$ varying Input Voltage, the Gain was determined graphically shown in fig below.

\section{Gain}

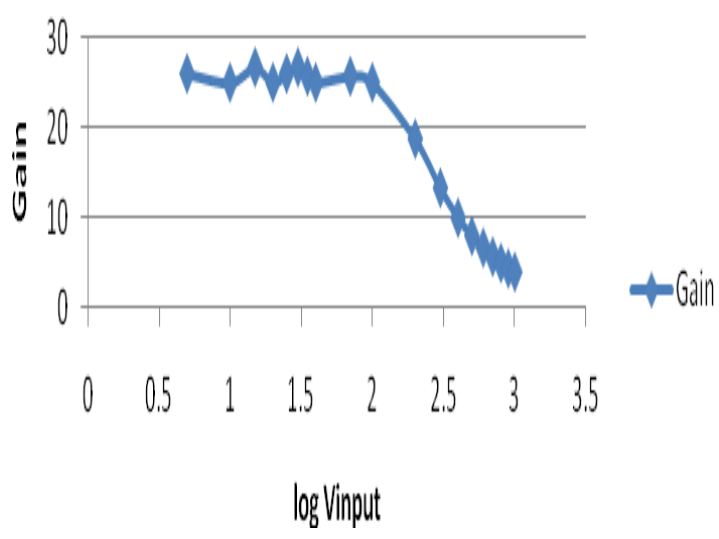

Figure4: the graph of Gain against Log of Input Voltage.

Fig above shows the graph of Gain against Log of Input Voltage. It indicated that when the input Voltage delivered into the amplifier increases this also produces a proportional amount of Output Voltage by amplifier and high Gain was also produced, From the range $0.69897-2$ of log Input Voltage, beyond this range Gain was gradually decreasing with increasing input Voltage, because the transistor reaches 
its maximum rating power, at this point called saturation point no longer used as amplifier it became switch.

At constant Resistor $\operatorname{Rg}(30 \Omega)$ and constant Input Voltage $(20 \mathrm{mV})$ varying input Frequency, the Gain was determined graphically shown in below.

\section{Gain}

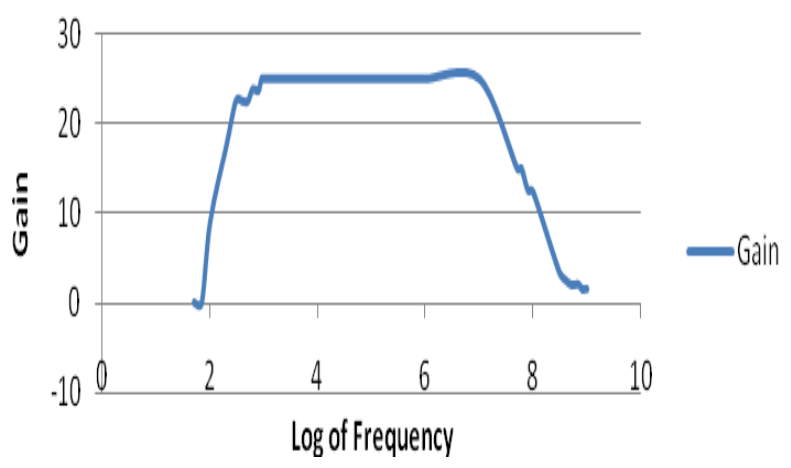

Figure5: A typical Frequency- versus-Gain curve

A typical Frequency- versus-Gain curve is shown in Fig below. While analyzing this curve, three value of frequency are important mid-frequency range ,Log 2.954242509 - Log 7, lower cut-off frequency, $\log 2.903089987$, upper cut-off frequency, $\log 7.698970004$.The cut-off frequencies are also called roll-off frequencies because at these frequencies the amplifier Gain starts rolling down from its midband value or maximum value. The frequency span between these two cut-off frequencies is called the passband or bandwidth (BW) of the amplifier. All frequencies lying between lower cut- off and upper cut - off are amplified almost equally.

\section{Conclusion}

The design and implementation of a 2N2222A transistor amplifier has been presented. The amplifier was simulated using Multisim 9 soft ware. The tests verified the performance of the amplifier. It indicates the resistance at which the amplifier instantaneously generates Gain, the rang of the Input Voltage at which the amplifier has different Output Voltage and different Gain, the rang it has constant Output Voltage but Gain was gradually decreasing with increasing Input Voltage which is called saturation point. The cut-off frequencies at which the amplifier's Gain starts rolling down from its midband value or maximum value, the frequency span between these two cut-off frequencies called the passband or bandwidth (BW) of the amplifier. The relationship between additional Resistor $\left(\mathrm{R}_{\mathrm{g}}\right)$, Input Voltage $\left(\mathrm{V}_{\text {in }}\right)$, frequency respond and Gain was determined graphically.

\section{REFERENCES}

[1] Abu-Rub, H., Malinowski, M., \& Al-Haddad, K. (2014). Power Electronics for Renewable Energy Systems, Transportation and Industrial Applications: Wiley, New Jersey, United States.

[2] Christopher, B. (2017). Hand Book of Physics: Volume 1: eBooks2go Incorporated.

[3] Elbert, B. (2008). Introduction to Satellite Communication: Artech House, Massachusetts, United States.

[4] Glisson, T. H. (2011). Introduction to Circuit Analysis and Design: Springer Netherlands, Salmon Tower Building New York City, United States.

[5] Kularatna, N. (2008). Electronic Circuit Design: From Concept to Implementation: CRC Press, Florida, United States.
[6] Kumar, N. (2004). Comprehensive Physics XII: Laxmi Publications, New Delhi, India

[7] layton, G. B., \& Winder, S. (2003). Operational Amplifiers: Elsevier Science, London and Oxford, UK.

[8] Mehta, R. (2008). Objective Electrical Technology: S. Chand Limited, New Delhi, india.

[9] Morris, A. S. (2001). Measurement and Instrumentation Principles: Elsevier Science, Amsterdam, Netherlands

[10] Pannenborg, A. E. (2012). Electrical Instruments / Elektrische Instrumente: Springer Berlin Heidelberg, New Delhi, india.

[11] Personnel, U. S. B. o. N. (1970). Gunner's mate G 3 \& 2.

[12] Puntambekar, A. A. (2010). Software Engineering And Quality Assurance: Technical Publications. Pg 2-32

[13] Shashidhar, K., \& House, S. B. (2013). Concepts of Electrical And Electronics Engineering: Sapna Book House (P) Ltd.

[14] Singh, M. D. (2008). Power Electronics: McGraw-Hill Education (India) Pvt Limited. Pg 1

[15] Avison, J. (2014). The World of Physics: Nelson.

[16] Chaudhary, S. (2014). Principles of Electronics: University Science Press.

[17] Dailey, D. J. (2011). Electronics for Guitarists: Springer New York.

[18] Gates, D. (2001). Introduction to Electronics: Delmar.

[19] Godse, A. P., \& Bakshi, U. A. (2009). Solid State Devices And Circuits: Technical Publications.

[20] Godse, U. A. B. A. P. (2009). Electronic Devices And Circuits: Technical Publications.

[21] Godse, U. A. B. A. P. (2010). Electronic Devices And Circuits I: Technical Publications.

[22] Joseph, C. L., Halkiadakis, E., Bernal, S., \& Maiullo, D. (2016). Modern Devices: The Simple Physics of Sophisticated Technology: Wiley.

[23] Knight, S. A., Bird, J. O., \& May, A. J. C. (2016). Electronics 3 Checkbook: The Checkbooks Series: Elsevier Science.

[24] Kramer, A. (2012). Math for Electricity \& Electronics: Cengage Learning.

[25] Nair, B. S., \& Deepa, S. R. (2013). Basic Communication and Information Engineering: I.K. International Publishing House Pvt. Limited.

[26] Patrick, D. R., \& Fardo, S. W. (2008). Electricity and Electronics Fundamentals: Fairmont Press.

[27] Silver, H. W., \& Wilson, M. (2008). The ARRL Extra Class License Manual for Ham Radio: ARRL.

[28] Godse, A. P., \& Bakshi, U. A. (2009). Electronics Circuits - I: Technical Publications.

[29] Pal, B. P. (2010). Guided Wave Optical Components and Devices: Basics, Technology, and Applications: Elsevier Science.

[30] Yan, J. (2015). Machinery Prognostics and Prognosis Oriented Maintenance Management: Wiley. 